\author{
Dossiê \\ TRIBUNAL DO SANTO OFÍCIO PORTUGUÊS, 200 ANOS APÓS EXTINÇÃO: \\ HISTÓRIA E HISTORIOGRAFIA
}

\title{
APRESENTAÇÃO \\ NOTAS SOBRE A INQUISIÇÃO PORTUGUESA: HISTÓRIA E HISTORIOGRAFIA
}

\section{SOBRE A TRAJETÓRIA DO SANTO OFÍCIO PORTUGUÊS}

Por meio da bula Cum ad nihil magis, assinada em 23 de maio de 1536, o papa Paulo III atendeu à solicitação do rei de Portugal, Dom João III, que realizava investidas no sentido de conseguir a autorização para implantação do Santo Ofício português. ${ }^{1}$ Tentativas ocorriam desde o reinado de Dom Manuel I, mais precisamente desde o ano de 1515, quando este monarca escreveu ao embaixador de Roma, Dom Miguel da Silva, pedindo que fosse enviada uma solicitação ao Papa Leão X, para que o pontífice criasse para Portugal um Tribunal da Inquisição, nos moldes de seu congênere espanhol. Diante das tensões entre os cristãos novos portugueses e espanhóis e, também, dos conflitos entre a população cristã e os conversos, Dom Manuel pretendia "tutelar a autonomia jurisdicional dos seus territórios, recusando as invasivas pretensões dos inquisidores castelhanos" (MARCOCCI, 2011, p. 23). Durante duas décadas, muitas foram as iniciativas, tanto da coroa portuguesa quanto de setores eclesiásticos no sentido de alcançar esse objetivo. ${ }^{2}$

Embora a bula papal tenha sido assinada em maio de 1536, apenas cinco meses depois, mais precisamente em 22 de outubro, ocorreu a cerimonia de publicação, na Catedral de Évora, cidade de habitação, na época, da corte portuguesa, na presença do inquisidor-geral, do rei, do cardeal, do cabido e todo o restante do clero e da população da cidade e arredores. A leitura da bula tornava públicos, aos ouvintes, o ato de criação da instituição, esclarecimentos sobre o caráter da Inquisição, bem como sobre os delitos de sua alçada. Conforme Marcocci e Paiva (2013), o Santo Ofício português começou a

\footnotetext{
${ }^{1}$ Arquivo Nacional da Torre do Tombo, Bulas, Maço 9, número 15, Bula Cum ad nibil magis do papa Paulo III dirigida aos bispos de Coimbra, Lamego e Ceuta pela qual os constitui seus comissários e inquisidores no reino de Portugal como também outra pessoa eclesiástica que o rei d. João III nomeasse para procederem contra os cristãos novos e mais pessoas que incorressem em crimes de heresia, com as penas declaradas. Para acesso online ao documento: https://digitarq.arquivos.pt/viewer?id=3908041

2 A historiografia portuguesa é rica em autores que se debruçaram sobre a trajetória de ações de setores do clero e da coroa portuguesa no sentido do estabelecimento do Santo Ofício português, bem como da resistência papal a essas iniciativas. O tema está presente em publicações do século XIX e princípio do século XX, de autoria de Antônio Joaquim Moreira, Alexandre Herculano e António Baião; nos estudos de Francisco Bethencourt (2000) sobre a História das inquisições em Portugal, Espanha e Itália; e na História da Inquisição Portuguesa (1536-18210, de Giuseppe Marcocci e José Pedro Paiva (2013). Sobre a trajetória da historiografia do Santo Ofício português, cf. Souza (2014, p. 25-35).
} 
funcionar no dia 22 de novembro de 1536, na pousada do Inquisidor-geral, Dom Diogo da Silva, espaço no qual foram ouvidas "testemunhas contra a cortesã cristã-nova Madalena de Oliveira. Em janeiro do ano seguinte, desencadearam-se os primeiros processos" (MARCOCCI; PAIVA, 2013, p. 35).

Ainda no ritual do estabelecimento, foi feita a leitura do Édito da Graça, que estabeleceu o prazo de 30 dias para que as pessoas que tivessem cometido crimes de heresia pudessem se apresentar diante do Santo Ofício, demostrando arrependimento. Ao término do tempo da Graça, "em 19 de novembro o inquisidor-geral publicou um monitório com descrição pormenorizada dos crimes sob jurisdição inquisitorial que deveriam ser denunciados ao tribunal" (BETHENCOURT, 2000, p. 25).

Desde o início, a alegação utilizada para o estabelecimento da Inquisição portuguesa era o crescimento das heresias junto aos cristãos novos portugueses. Embora a alçada da Inquisição diga respeito a uma variedade de crimes contra a fé (judaísmo, maometismo, protestantismo, molinismo, deísmo, críticas aos dogmas etc), e estivessem contemplados, também, entre os delitos previstos, práticas que atentassem contra a moral cristã e os bons costumes (bigamia, sodomia, feitiçaria, solicitação etc), o objetivo principal da Inquisição portuguesa era, mesmo, perseguir e punir práticas de judaísmo em meio aos neófitos do cristianismo. Até a primeira década do seiscentos, o Santo Ofício português também se preocupou com desviantes identificados com os erasmianos, com luteranos e calvinistas e com o avanço das ideias reformadas, como esclarece Elisete da Silva (2020, p. 38). A tentativa de controle por meio de leituras proibidas está em destaque nesse período, como nos séculos seguintes.

O crescimento do judaísmo em Portugal esteve associado à conversão forçada dos judeus, banidos da Espanha pelos reis católicos. Em dezembro de 1496, Dom Manuel publicou um decreto de expulsão, estabelecendo um prazo de dez meses para que judeus e mouros deixassem Portugal, como esclarecem Marcocci e Paiva (2013, p. 25):

4 de dezembro de 1496, em Muge, onde se encontrava a corte de D. Manuel I, fora anunciada a expulsão dos judeus e muçulmanos residentes em Portugal, sem que a sua coexistência com a maioria cristã tivesse provocado, no século $\mathrm{XV}$, tensões semelhantes às ocorridas em Castela e Aragão. Ali, em 1492, os Reis católicos, Fernando e Isabel os judeus (mas não os muçulmanos).

A medida adotada por D. Manoel, atendia ao disposto no contrato de casamento entre o rei português e Isabel de Aragão, filha dos reis espanhóis. Contudo, ao término do prazo previsto, em fins de outubro do ano seguinte, os judeus que ainda estavam em Portugal foram proibidos de sair do país:

Em fins de outubro de 1497 expirou o prazo para que os judeus deixassem Portugal. Milhares deles, que se dirigiram para o porto, receberam o comunicado de que, uma vez que já havia se findado o prazo, eles seriam considerados, a partir de então, escravos do rei. A ordem foi revogada logo em seguida, mas o rei ordenou que todos fossem batizados à força. Esse episódio justifica, em parte, o grau elevado de criptojudeus em Portugal e seus domínios (SOUZA, 2008, p. 90).

O presente texto, de caráter introdutório, panorâmico e de apresentação não tem por objetivo trazer minúcias da história de quase trezentos anos de existência do Santo Ofício português, não só pela longevidade da instituição, mas também pela extensão geográfica de sua atuação: a Inquisição lusa foi 
atuante não apenas em Portugal, mas em todo o território ultramarino do reino, nos continentes americano, africano e asiático. Durante o período de existência do Santo Ofício português, existiram três tribunais, com sedes em Lisboa (1536-1821), Évora (1536-1821) e Coimbra (1541-1821). ${ }^{3}$ O primeiro tinha por jurisdição, além de regiões do reino, também o Brasil, ilhas do Atlântico e posições portuguesas na costa ocidental da África. O único tribunal fora de Portugal foi o de Goa, na Índia, instituído em 1560, que tinha também sob sua jurisdição a costa oriental africana.

Restrições impostas pelo papa, na primeira década de existência da Inquisição portuguesa, não agradavam D. João III, pois feria a sua autonomia. Como destaca Antônio José Saraiva (1994), dos quatro inquisidores, três eram nomeados diretamente pelo papa e ao monarca era autorizado escolher apenas um. Outros indicativos de cerceamento de autonomia da monarquia portuguesa pelo papado são elencados pelo autor:

Além disso, determinava que durante três anos os nomes das testemunhas de
acusação não fossem secretos, e que durante dez anos os bens dos condenados não
fossem confiscados. Os bispos teriam os mesmos poderes que os inquisidores no
conhecimento das heresias. Por intermédio do seu núncio em Lisboa, o Papa
reservava-se o direito de fiscalizar o cumprimento da bula, de conhecer os processos
quando o entendesse e de decidir em última instância (SARAIVA, 1994, p. 50).

O controle do sumo-pontífice sobre a Inquisição portuguesa, sobretudo no que se refere à condução dos processos contra cristãos novos, foi superado apenas com a bula Meditatio Cordis, publicada em julho de 1547, que dotou o Santo Ofício português "das faculdades ambicionadas, sobretudo maior autonomia face a Roma e possibilidade de realizar processos secretos anulando ainda os poderes da bula de 1536 que tinha dado a vários bispos inquisidores, agora todos exclusivamente concentrados em D. Henrique" (MARCOCCI; PAIVA, 2013, p. 38). ${ }^{4}$

Na década de 1540, marcada por conflitos, várias bulas e breves foram publicados e revogados: "Chegou-se mesmo a levantar a possibilidade de um rompimento [...] com Roma. A última cartada de Paulo III foi a promulgação de um breve datado de 8 de janeiro de 1549, em que abolia o segredo das testemunhas, porém nunca entrou em vigor em terras lusitanas" (SOUZA, 2014, p. 56). 5

O tribunal do Santo ofício português foi, ao mesmo tempo, régio e eclesiástico e, desde o momento de seu nascimento, foi de fundamental importância para a política de centralização do poder monárquico. Mas, apesar de ter conseguido consolidar a tão sonhada autonomia, a Inquisição portuguesa e as suas ações contra os cristãos novos permaneceram, até princípio do século XVII, sob o controle de

\footnotetext{
${ }^{3}$ Foram também estabelecidos mais três tribunais, porém todos eles tiveram vida curta: o do Porto, criado em 1536 e extinto em 1545; o de Lamego (1541-1546) e o de Tomar (1541-1544).

${ }_{4}^{4}$ Em 1539, D. Diogo da Silva renunciou à carga de inquisidor geral e em seu lugar foi nomeado o Cardeal Dom Henrique irmão do rei D. João II, arcebispo de Braga e eleito cardeal de 1545, que tomou posse em 3 de julho de 1539. D. Henrique sucedeu a D. Sebastião e foi coroado como Rei Henrique I, permanecendo no trono até a sua morte, ocorrida em janeiro de 1580. Esse ano marca o início do período de União das Coroas Ibérica, sob o comando do rei Felipe II da Espanha e I de Portugal.

5 "[Os] conflitos, internos e externos, relacionados ao Tribunal continuam por longo tempo, e somente na segunda metade do século XVIII, no período pombalino, a Inquisição Portuguesa parece ter sido completamente dominada pelo Estado" (SOUZA, 2014, p. 56).
} 
Roma. Exemplo disso é Perdão Geral de 1605, concedido pelo papa Clemente VIII, o quarto perdão emitido por esse mesmo papa, segundo Elias Lipiner (1977). Por meio desse breve, foram beneficiados 70 homens e 85 mulheres que se encontravam presos nos cárceres do Santo Ofício. ${ }^{6}$ Dentre as mulheres que alcançaram a liberdade por força desse ato, estavam três moradoras da Bahia todas da família Antunes, sendo duas filhas - Beatriz e Leonor - e uma neta - Ana Alcoforada - do casal Ana Rodrigues e Heitor Antunes. ${ }^{7}$

Ainda referente ao Perdão de 1605, em um livro de correspondência da Inquisição de Lisboa encontramos anotações de uma carta enviada para a Bahia, datada de 16 de março de 1605, informando que foi remetido um maço com documentação destinada ao bispo do Brasil, Dom Constantino Barradas, com uma missiva do "Senhor Inquisidor Geral" - na época, D. Pedro de Castilho - e da Mesa inquisitorial avisando "que as pessoas que estivessem lá presas por ordem do Santo Ofício, as mandasse soltar" e tornar seus bens, pagando somente o que tinham custado com suas pessoas. ${ }^{8}$

No reinado de Dom João IV, tiveram lugar vários conflitos entre a coroa e poder inquisitorial, relacionados à guerra com a Espanha, ao reconhecimento da restauração da monarquia portuguesa e, ainda, por conta das ações frente aos cristãos novos envolvendo o padre Antônio Vieira. Esclarece Novinsky (1978, p. 13):

Durante o reinado de D. João IV, quando atrás do monarca soprava a voz do padre Antonio Vieira, a Inquisição se viu seriamente ameaçada e privada de seus lucros. Os desentendimentos entre Coroa e Inquisição alcançaram então seus extremos. Apesar da indignação dos Inquisidores com a formação da Companhia de Comércio para o Brasil (1649) e o Alvará que isentou do confisco os mercadores cristãos novos acionistas da Companhia, D. João IV teve a coragem de desafiar a Inquisição e mandou retirar desta a autoridade administrativa do Fisco, ordenando que passasse para o Conselho da Fazenda, alegando ainda que não era conveniente que os Inquisidores se "distraíssem" com negócios alheios a sua função principal, visto haver pessoas que atrevidamente punham em dúvida o escrúpulo usado no manejo dos seqüestros (1655).

No bojo da relação entre monarquia portuguesa e o tribunal do Santo Ofício, foi revelado, em 1641, um complô articulado pelo então inquisidor geral, D. Francisco de Castro, com o intuito de assassinar o rei. Para Saraiva, essa conspiração tinha por objetivo reestabelecer a união ibérica. O episódio insere-se na luta por poderes entre o rei e papa, do qual o Inquisidor geral era o representante:

O Inquisidor-Geral tinha a qualidade e os poderes de delegado do Papa, podendo inclusive lançar excomunhões reservadas à Santa Sé. Era, no entanto, designado pelo Rei, limitando-se o Papa a confirmar essa designação. Uma vez nomeado e

\footnotetext{
${ }^{6}$ Coleccão de Listas impressas e manuscritas dos Autos de Fé públicos e particulares da Inquisição de Lisboa, Évora, Coimbra e Goa. Corrigida e anotada por Joaquim Antonio Moreira, 1863. 4 v. (613 f.; 428 f.; 365 f.; 308 f.). Disponível em: https://purl.pt/15393

${ }^{7}$ A história dessa família é conhecida pelos registros da primeira visitação do Santo Ofício em terras brasileiras, ocorrida entre 1591 a 1595, tendo como visitador foi Heitor Furtado de Mendonça. Muitos membros da família foram denunciados e quatro mulheres foram enviadas presas para Lisboa, sendo que a matriarca, já octogenária, não resistiu aos suplicio e morreu nos cárceres dos Estaus, em Lisboa. Além dos filhos, sete netos também foram à mesa inquisitorial para testemunhar: Ana Alcanforada, Valentim de Faria, Felipa de Faria, Custódia de Faria, Isabel Antunes, Lucas de Escobar e Beatriz Teles. O historiador Angelo Adriano de Farias Assis, em seu livro Macabéias da Colônia (2012) apresenta, com riqueza de detalhes, a trajetória dessa família nas malhas da Inquisição.

8 Arquivo Nacional da Torre do Tombo (ANTT), Tribunal do Santo Ofício (TSO), Inquisição de Lisboa (IL0, Livro 18, fl. 254.
} 
confirmado, o Rei não tinha mais qualquer poder ou controlo sobre este seu súbdito que assumia dentro do Reino os poderes e a autoridade do mesmo Papa em matéria de Fé. Embora nomeasse o Inquisidor-Geral, o Rei não podia destituí-lo, fossem quais fossem as circunstâncias (SARAIVA, 1994, p. 159).

Outro episódio decisivo relativo às ações inquisitoriais diz respeito à suspensão dos processos da Inquisição portuguesa, em 1674, por meio do breve Cum dilecti, do Papa Clemente X. O poder só foi restituído ao Santo Ofício português em 1681, já no pontificado de Inocência XI. Segundo Marcocci e Paiva (2013, p. 204), depois “do perdão geral de 1604-1605, a suspensão dos processos e cessação dos autos de fé foi a maior derrota da inquisição".

Para uma melhor compreensão sobre os afazeres inquisitoriais, sobretudo no que se refere às atividades repressivas, trazemos um quadro geral baseado na análise de documentos e em informações presentes na historiografia referente aos tribunais de Lisboa, Coimbra, Évora e Goa. No período que se estende de 1536 a 1605, desde a instalação do tribunal em Portugal até a concessão do Perdão Geral, foram processados mais de 10 mil indivíduos, sendo que aproximadamente 7,4\% foram condenados à morte. ${ }^{9}$ De 1606 a 1674, período que começa no ano seguinte à concessão do Perdão Geral e termina com a suspensão da Inquisição pelo papa, foram sentenciados pelo Santo Ofício português mais que o dobro do período anterior: 22.481 pessoas, das quais 863 foram relaxadas. ${ }^{10}$ Após o retorno das atividades inquisitoriais, em 1681, até 1750 - início do reinado de D. José I e da ascensão do Marquês de Pombal à condição de secretário de Estado - foram computadas 10.551 pessoas processadas, com $3,7 \%$ condenadas à morte. Embora, nesse último período o número de processados tenha ficado próximo ao da primeira etapa de funcionamento da Inquisição, o percentual de relaxação foi bem menor, cerca da metade. A partir da década de sessenta dos setecentos, ocorreu uma queda acentuada no número de condenados pela Inquisição. Tomando como base os dados fornecidos por Bethencourt (2000), entre os anos de 1751 a 1767, o Santo Oficio português sentenciou pouco mais de 1590 pessoas, das quais foram relaxadas $3,6 \%$.

A média anual de processos correspondente aos quatro tribunais, em cada um desses quatro períodos, foi consolidada por Bethencourt (200, p. 312): “37 entre 1536 e 1605, 81 entre 1606 e 1674, 35 entre 1675 e 1750, e 23 entre 1751 e 1767”. Comparando esses números com os de sentenciados das inquisições Espanhola e Italiana, o autor conclui que "as médias anuais dos processos portugueses são sempre superiores, em todos os períodos, à medias espanholas e italianas, embora se deva atentar às enormes lacunas de fontes verificadas nesses últimos casos" (BETHENCOURT, 2000, p. 321).

A maior parte dos delitos apontados nos processos do Santo Ofício português dizia respeito às práticas judaizantes, contudo cada localidade do império deve ser examinada em suas particularidades, como pode ser observado nos artigos que compõem o dossiê que ora apresentamos.

\footnotetext{
${ }^{9}$ Segundo Bethencourt (2000), nesse período 755 indivíduos foram relaxados à justiça secular.

${ }^{10}$ Dados fornecidos por Francisco Bethencourt (2000). O autor informa que, no momento da realização da pesquisa, não foi possível computar o número de relaxados da Inquisição de Goa referentes ao período de 1606 a 1684.
} 
A partir da década de setenta do século XVIII, as atividades repressivas do Santo Ofício português reduziram significativamente e várias são as razões. Em 25 de maio de 1773, foi publicado um decreto régio pondo fim à distinção entre cristãos-novos e cristãos-velhos. No ano seguinte, entrou em vigor o último regimento da Inquisição, que incorporou os anseios de reforma administrativa do Estado português e das suas relações com a Igreja. ${ }^{11}$

O novo regimento trouxe elementos que julgamos importante destacar aqui. Ele contribuiu para a redução das atividades inquisitoriais e, consequentemente, para o arrefecimento do medo em relação ao que se entendia como marca do horrendum tribunale: o uso de tortura. Outras modificações importantes foram: o fim do segredo processual e a modificação no tratamento de alguns crimes, a exemplo das “chamadas práticas mágicas, feitiçarias, superstição, adivinhadores, proporcionadores 'racionais' de malefícios e astrologia judiciária de feitiçaria" (SOUZA, 2014, p. 242).

A prática de tortura era já tratada, naquele momento, como "estranha dos pios e misericordiosos sentimento da Igreja Mãe", e era condenada por alguns por levar a falsas confissões. Porém, ela continuou a ser admitida "nos casos de heresiarcas ou dogmatista negativos e que ocultavam os nomes das pessoas que com eles prevaricaram, mantendo o que estava prescrito no Regimento anterior quanto ao modo de sua aplicação" (MARCOCCI; PAIVA, 2013, p. 354-355).12

Em relação ao fim do segredo processual, é importante ressaltar que, desde o início das atividades inquisitoriais, o segredo, juntamente com o confisco de bens que impedia o acesso à herança por parte dos filhos menores dos condenados, foi alvo de severas críticas e pesados argumentos daqueles que se opuseram às práticas da instituição. Segundo Bethencourt (2000, p. 340), o segredo do processo "é o que distingue mais claramente o processo inquisitorial das práticas processuais da época: os acusados não podiam conhecer os nomes de seus denunciantes ou testemunhas de acusação, nem sequer as circunstâncias de tempo e lugar dos crimes imputados". O indivíduo, quando era preso, não sabia o motivo da denúncia, quais pessoas o denunciaram e nem mesmo o delito que havia cometido. A falta completa de informações levava o réu ao desespero e, instado a dizer o que os inquisidores queriam ouvir, em muitos momentos entregavam amigos e familiares. Uma parte considerável das denúncias por práticas de judaísmo tiveram origem dentro dos cárceres do Santo Ofício. Analisando o processo de Alexandre Henriques - bem como a história de vida de sua mãe e irmãos -, enviado preso de Salvador para Lisboa em 1734, verificamos que as denúncias contra sua família foram todas feitas de dentro dos Estaus. ${ }^{13}$ Ele próprio, quando tinha 16 anos de idade, em 1706, procurou a Mesa Inquisitorial, juntamente com sua irmã, Maria Nunes, para confessar que judaizavam e que havia sido iniciado na

\footnotetext{
11 O regimento anterior esteve em vigência por 134 anos, desde 1640. Foi elaborado no final do período da união das coroas ibéricas. Antes dele, a Inquisição portuguesa teve dois outros: o de 1552 e o de 1603.

12 A referência feita acima pode ser observado no Livro II (Da ordem do judicial do Santo Ofício), e Capítulo XIV, pelo qual ficou determinado de "como há de proceder com os réus, que houveram de ser postos a tormento, e na execução dele. Marcocci e Paiva (2013, p. 255) acrescentam outras mudanças importantes, como a "suspensão da inabilitação dos condenados e dos seus descendentes; condenação da impossibilidade de recursos para o Tribunal Superior da Coroa, agora admitido".

${ }^{13}$ O palácio dos Estaus (ou Estaos) foi a sede do Conselho Geral do Santo Ofício e da Inquisição de Lisboa até a extinção do Santo Ofício. Localizado na praça do Rossio (atual praça Dom Pedro IV), foi construído em meados do século XV para servir como albergue para pessoas da corte portuguesa sem residência e estrangeiros representes de outros reinos.
} 
religião judaica por sua mãe, Clara Rodrigues, e por sua madrinha, Leonor Rodrigues, ambas sentenciadas pelo Tribunal. ${ }^{14}$ Além dele e da mãe, foram presos, também, duas irmãs e um tia.

O último regimento do Santo Ofício português, que entrou em vigência em 14 de agosto de 1774, era, também, resultado do reformismo ilustrado pombalino e pretendia "dar uma roupagem diferenciada à Instituição, torná-la instrumento em defesa do Estado, coerente com o momento histórico e tipo de governo que Portugal vivenciava, embora a manutenção de tal Instituição no 'século das luzes' não deixava de ser contraditória" (SOUZA, 2014, p. 242). ${ }^{15}$ No novo regimento, a crença em práticas de feitiçaria passou a ser atribuída à ignorância, ao fanatismo, estimulada por textos e autores que estimulavam o obscurantismo, dentre os quais o Malleus Maleficarum, manual escrito pelos dominicanos Heinrich Kraemer e James Sprenger, no século XV; uma obra atribuída ao Fr. Jeronimo Savanarola; além de escritos de padre Antônio Vieira e do frei Thomas Campanela. O regimento de 1774 traz um arrazoado sobre a impossibilidade do pacto demoníaco, por não ser verossímil e não condizente com a razão:

Porquanto pela dedução e combinação de tudo o referido, se concluiu teológica, jurídica e geometricamente, que os feitiços, sortilégios, adivinhações, encantamentos e malefícios, depois da redenção do mundo foram manifestamente imposturas maquinadas: ou por pessoas poderosas que para santificarem, ou fazerem formidáveis as suas cobiçosas tiranias, e lisonjearem as suas depravadas paixões se serviram dos magos ou mágicos, e dos sacerdotes gentis, como de instrumentos próprios para estabelecerem, sobre a ignorância e fanatismo dos povos, a cega sujeição as suas cureis atrocidades. ${ }^{16}$

A incredulidade na existência das práticas mágicas conduz à admissão de que os réus que insistissem na veracidade dos efeitos dessas ações deveriam ser tratados com insanos, alienados:

Só pode ser miseráveis efeitos de uma crassa ignorância, e de uma furiosa loucura, agitadas por um daqueles ardentes fanatismos, que intemperado as cabeças dos homens, ou deixam cegos à luz da verdade, e indisposto para ouvirem as vozes da razão: Ordenamos: que os réus que se acharem nos referidos casos, sejam definitivamente julgados por loucos, sem necessidade de outra prova ou exame: Que sejam como tais remetidos ao Hospital Real de todos os santos; Que nele fiquem reclusos nos Cárceres dos doidos enquanto o Conselho Geral não mandar o Contrário. ${ }^{17}$

O estudo da legislação inquisitorial é de grande valia para compreender a dinâmica legal de funcionamento da instituição. ${ }^{18}$ Os regimentos da Inquisição portuguesa, em particular, são também fundamentais ao estudo do Santo Ofício em sua trajetória de quase três séculos de existência, período de grandes mudanças nas mentalidades. São fartos os registros sobre processos inquisitoriais, processos de habilitação, instruções a ministros e outros, o que nos leva a identificar como essa legislação foi colocada em prática. Também, por meio dessa mesma documentação, percebemos as diversas maneiras como as suas determinações eram

\footnotetext{
14 ANTT, TSO, IL, Processo 3432.

${ }^{15}$ Sobre o contexto político no qual se insere a publicação do Regimento de 1774, cf. Falcon (1992).

16 REGIMENTO do Santo Ofício da Inquisição do Reino de Portugal, 1774, Livro III, Título XI.

${ }^{17}$ REGIMENTO do Santo Ofício da Inquisição do Reino de Portugal, 1774, Livro III, Título XI, Capítulo II.

18 Para mais informações, cf. Siqueira (1996) e Mott (1990).
} 
burladas, seja pela população em geral ou pelos próprios agentes habilitados. Enfim, o conjunto documental que compõe o fundo do Santo Ofício, incluindo os regimentos, nos revela muito da trajetória dessa instituição, desde o princípio até a sua extinção.

\section{UMA REDE DE AGENTES INQUISITORIAIS}

Fora dos tribunais de distrito, as ações inquisitoriais estiveram ao encargo de uma rede de agentes, constituída principalmente por Comissários e Familiares. Essa rede começou a se formar nos últimos anos do século XVI e a sua presença se intensificou a partir do XVII. Em algumas localidades do império só veio a se consolidar no final dos seiscentos e princípio dos setecentos. Sendo assim, no primeiro meio século de funcionamento do Santo Ofício português, suas ações fora do reino ocorreram por meio de agentes delegados e, de maneira mais efetiva, quando da realização das visitações autorizadas pelo Conselho Geral (CG). Órgão máximo da hierarquia inquisitorial, o Conselho Geral era presidido pelo Inquisidor-mor e composto por deputados. Foi instituído em meados de 1569 pelo Cardeal Dom Henrique e pelo Regimento elaborado em 1570. A criação do CG objetivava manter um controle maior dos tribunais de Lisboa, Évora e Coimbra sobre o funcionamento do corpo de agentes. ${ }^{19}$ Com a finalidade de fiscalizar e controlar o mundo luso, dentro e fora de Portugal, o Conselho organizou as diversas visitações do final do século XVI, intenção já registrada em 1588, quando foi externado o interesse na realização de visitas nas ilhas da Madeira, Açores, Brasil, Cabo Verde e São Tomé. Foi como parte desse projeto que ocorreu a primeira visitação da inquisição às terras da América portuguesa, no ano de 1591, com a chegada do primeiro visitador Heitor Furtado de Mendonça. ${ }^{20}$ Sobre o momento do desembarque do Heitor Furtado de Mendonça em Salvador, expõe Luiz Mott (2010, p. 19):

Salvador, 50 anos depois de fundada, possuía por volta de 800 vizinhos brancos e três vezes mais negros e índios, quando no ano do Senhor de 1591 desembarca em seu porto inesperado visitante: o Licenciado Heitor Furtado de Mendonça, Deputado do Santo Ofício da Inquisição. A notícia de tão temível visita deve ter-se alastrado a trote de cavalo pelos mais de 40 engenhos espalhados pelo Recôncavo, deixando a população em palpos de aranha.

No mesmo ano de 1591, parte para as ilhas dos Açores e da Madeira o visitador Jerônimo Teixeira; em 1596, foi a vez do padre Jorge Pereira visitar Angola. No Brasil, ocorreram mais três visitas: a segunda, restrita à Bahia (Salvador e Recôncavo), ocorreu entre 1618 e 1620; outra, nas capitanias do sul, aconteceu entre 1627 e 1628. Já no século XVIII, entre 1763 e 1769, foi realizada a visitação do Grão-Pará. ${ }^{21}$

\footnotetext{
19 O controle do Conselho Geral em relação ao corpo de funcionários é perceptível quando analisamos a troca de correspondência entre esse órgão e os tribunais de distrito. Essas correspondências fazem parte de dois conjuntos documentais identificados como correspondências expedidas (1575-1819) e correspondências recebidas (1562-1770), além de documentos avulsos que fazem parte dos acervos dos tribunais.

${ }^{20}$ Já na primeira década do século XX, Capistrano de Abreu (1922) dedicou-se a organizar uma importante publicação sobre a primeira visitação. Sobre o tema cf, também, Vainfas (1997).

${ }^{21}$ Muitos são os estudos sobre as visitações do Santo Ofício em terras brasileiras. Deixamos aqui algumas leituras indispensáveis para um melhor conhecimento do tema: Pereira (2011); França e Siqueira (1963), além de Lapa (1978).
} 
Contudo a presença mais efetiva da Inquisição nas terras de ultramar se deu, mesmo, por meio da formação de uma rede de agentes. A historiografia portuguesa e brasileira sobre Inquisição é rica em detalhes sobre a ação desses agentes, tanto a partir de uma perspectiva mais geral, no que refere ao processo de estabelecimento, estrutura e procedimentos da rede, quanto em uma perspectiva mais específica, em escala de regiões, cidades ou pequenas localidades. ${ }^{22}$ No universo mais restrito, os agentes locais fizeram a ponte, foram os "pontas de lança" dos tribunais aos quais estavam subordinados.

\section{ACESSO À DOCUMENTAÇÃO INQUISITORIAL E NOVAS PESQUISAS}

A documentação resultante das ações inquisitoriais é de grande valia para os estudos da história colonial, sobretudo com relação às primeiras décadas de colonização efetiva, cujas fontes são mais escassas. Essa documentação nos permite analisar não apenas as questões de ordem religiosa, mas também as relacionadas ao poder e à dominação econômica, à sociabilidade e à vida cotidiana. Com base nessas fontes, já no início da década de setenta do século XX, temos os primeiros trabalhos publicados, com destaque para a produção de Sonia Siqueira e Eduardo d'Oliveira França. Foram eles, conforme Ângelo Adriano, que lançaram as bases da historiografia brasileira sobre a Inquisição.

Siqueira e França foram os responsáveis pela publicação - precedida de um vasto e importante texto introdutório acerca do papel e presença dos cristãos-novos nos domínios portugueses e além, em especial o luso trópico, durante a Modernidade das confissões referentes à segunda visitação do Santo Ofício ao Brasil, iniciada em 1618 e que duraria cerca de dois anos, com raio de ação sobre a cidade do Salvador da Bahia de Todos os Santos e o seu Recôncavo, sob a responsabilidade do visitador Marcos Teixeira (ASSIS, 2015, p. 12). ${ }^{23}$

Nas décadas seguintes as pesquisas de Anita Novinsky, Luiz Mott, Laura de Melo e Souza e Ronaldo Vainfas produziram excelentes obras "impulsionadas pela riqueza das fontes e pelas correntes historiográficas ligada à história cultural e à história das ideias" (FEITLER, 2007, p. 11), influenciando toda uma geração posterior, não só na perspectiva de funcionamento da máquina inquisitorial, mas principalmente nos estudos dos crimes da alçada do Santo Ofício: judaísmo, feitiçaria, sodomia, solicitação, bigamia, "protestantismo", dentre outros. Pelas características da vasta produção historiográfica e para não cometermos injustiças é impossível elencarmos todas as valiosas contribuições dos investigadores brasileiros para os estudos inquisitoriais.

A atual geração de investigadores tem se beneficiado das novas tecnologias que, por meio do Projeto Inquisição on-line do Arquivo Nacional da Torre do Tombo que, em 2007, deu início ao processo de digitalização e posterior disponibilização da documentação produzida pelo tribunal lisboeta, segundo Calainho (2019, p. 182), “o maior dos tribunais regionais, e que tinha, sob sua jurisdição, no ultramar, o Brasil, as ilhas dos Açores e Madeira, Angola e regiões do Oriente, e portanto o mais procurado pelos pesquisadores dado o volume de territórios que abarcava".

22 Cf. Mott (2010); Wadsworth (2007); Calainho (2006); Feittler (2007); Souza (2014); Vaquinhas (2010); Rodrigues (2011).

${ }^{23}$ Sobre a historiografia referente ao Santo Ofício português, cf., também, Souza (2014, p. 25-35) e Assis (2015). 
Da Inquisição de Lisboa (IL) se encontram disponíveis em meio digital mais de 19 mil documentos, sendo 90\% de processos inquisitoriais. A partir de 2011, a digitalização foi ampliada para o subfundo do Conselho Geral do Santo Ofício, com as diligências de habilitandos a diversos cargos do Tribunal do Santo Ofício (Comissário, Qualificador, Notário, Visitador de nau e, predominantemente, Familiar). Esta série documental, compostas por mais de 30 mil processos, inclui também as habilitações incompletas, que calculamos um pouco mais de 5 mil documentos.

A documentação online do Tribunal do Santo Ofício português hoje permite ampliar as pesquisas, mediante a democratização do acesso as fontes inquisitoriais, e a dinamização da produção historiográfica, visto que os investigadores têm a possibilidade de principiar suas investigações ainda no início da vida acadêmica, em trabalhos de iniciação cientifica, trabalhos de conclusão de cursos e pósgraduação. Hoje já temos uma geração de pesquisadores que começam, dessa maneira, a labutar no site do Arquivo Nacional da Torre do tombo online.

\section{SOBRE O DOSSIÊ “TRIBUNAL DO SANTO OFÍCIO PORTUGUÊS, 200 ANOS APÓS EXTINÇÃO: HISTÓRIA E HISTORIOGRAFIA"}

O dossiê "Tribunal do Santo Ofício português, 200 anos após extinção: História e Historiografia" foi projetado com o objetivo de contribuir com os estudos inquisitoriais, sobretudo nesse momento em que investigadores de diversas partes do mundo têm discutido a história do tribunal e colaborado para enriquecer, ainda mais, a historiografia relativa à instituição. Os artigos aqui apresentados - dispostos na ordem cronológicas e da temática mais ampla para os estudos de caso mostram a presença da inquisição portuguesa nos continentes americano, africano e asiático.

Começamos, então, pelo texto de Eduardo Borges de Carvalho Nogueira, "Homens profanos: fluidez identitária entre renegados 'portugueses' na Índia”. O autor trabalha com estudo da trajetória de três homens, naturais do reino, que foram condenados por apostasia. O primeiro estudo diz respeito a Antônio Camacho, natural de Lisboa, mestre-escola de profissão, que foi para Goa no início da segunda metade do século XVI. O crime cometido foi o de bigamia, pois, já casado em Lisboa, o homem contraiu segundo matrimônio com uma mestiça nas terras luso-indianas. Os outros dois indivíduos estudados por Borges são Jorge Cardoso de Mendonça e Gonçalo Toscano, ambos também apostatas aos olhos da Igreja. O primeiro "tornou-se mouro, inclusive sofrendo a circuncisão", vestindo-se à mourisco, realizando cerimonias islâmicas e, mesmo depois de ter se apresentado ao tribunal em 1590, abjurado em auto-de-fé na Sé de Goa e absolvido pelo Santo Ofício, novamente se tornou um mouro. Gonçalo Toscano não conseguiu sucesso nem mesmo nos seus intentos de apóstata, pois não conseguiu ser visto como pessoa de confiança entre os islâmicos, tendo sido preso como suspeito de ser cristão. Destacamos algumas semelhanças entre os casos estudados: primeiro, o fato de os três homens terem indicado como motivo para a apostasia a necessidade de sobreviver no mundo islâmico, já que, como católicos, estavam fadados a morrer de fome; em segundo lugar, o fato de que os três homens tiveram seus nomes 
"alterados aquando de sua passagem ao Islâ", além de andarem com indumentária "à mourisca". Tanto Mendonça como Toscano serviram à força islâmica. Enfim, o texto traz elementos importantes não só para pensar questões relativas à ortodoxia como é rico em informações acerca das tensões entre cristãos e muçulmanos na índia e, também, no mediterrâneo.

"Sodomia faeminarum: a Inquisição e a alforria do lesbianismo no mundo" é o segundo artigo, mais uma importante colaboração de Luiz Mott para os estudos inquisitoriais, contribuição que foi iniciada nos primeiros anos da década de oitenta do século XX, com a publicações de artigos e livros resultantes das consultas da documentação do Santo Ofício português. $O$ texto aqui publicado, que tem como objetivo central levantar questões sobre a perseguição e penalização à homossexualidade feminina, parte da análise de um documento escrito pelo Tribunal de Goa, em 1646 e dos debates, entre os inquisidores, sobre o caráter da sodomia feminina. Como suporte para a discussão do tema, o autor visita uma vasta produção de textos dos séculos XVI e XVII, nomeadamente a literatura galega e os cancioneiros populares, com destaque para um poema de Gregório de Matos intitulado "Nise: A uma dama que macheava outras mulheres". Rica também é a incursão que Mott faz pela legislação que entra em vigência no império português até meados dos seiscentos, tanto as Ordenações do Reino (Afonsinas, Manuelinas e Filipinas) como os regimentos inquisitoriais (até o penúltimo, que entrou em vigor em 1640), destacando a importância de cada um desses documentos para a qualificação dos inquisidores no que se refere às relações sexuais entre mulheres. $\mathrm{O}$ autor conclui que relações entre as "filhas de Eva" não pertenciam à condição de "sodomia perfeita", estando, portanto, excluídas do delito da pena capital, ou seja, da morte na fogueira. Além do aporte jurídico, o autor - que também é organizador do dossiê relaciona um conjunto de obras de teólogos que alimentam a discussão sobre o "homoerotismo lésbico".

Ainda sobre o século XVII, apresentamos o texto "Mulheres africanas nas redes dos agentes da Inquisição de Lisboa: o caso de Crispina Peres, em Cacheu", de Vanicléia Silva Santos. Por meio de processos inquisitoriais e relatos de viajantes, autora aborda a trajetória de vida e o papel de uma mulher comerciante em Cacheu, cidade considerada a mais portuguesa da Guiné, com intensas relações comerciais com África, Europa e Brasil. Crispina Peres e seu marido possuíam "estalagem de estrangeiros", casas de aluguel, navio mercante e "muitos homens e mulheres feitos cativos para serem exportados". Além disso, ela era uma pessoa muito influente na região. Essa influência ficou bem demostrada quando as pessoas da nação Papel ameaçaram invadir Cacheu na noite de sua prisão. Conforme Vanicleia Santos, o processo contra Crispina foi um subterfugio, com objetivo de eliminá-la como concorrente comercial, tendo em vista que foram 21 pessoas denunciadas, mas apenas ela foi presa, enviada para Lisboa e condenada pelos crimes de feitiçaria, uso de ritos de gentilidade e de bolsas de mandingas. A história dessa mulher é um elemento importante para a compreensão das relações comerciais estabelecidas no período de expansão do tráfico transatlântico de escravizados, bem como para os estudos de gênero, raça e religião.

O quarto artigo que compõe o dossiê, "A família cristã-nova Bernal Nunes de Miranda: entre fronteiras, religiosidades e a Inquisição na Bahia" foi escrito por Ademir Schetini Júnior e trata da 
perseguição da Inquisição portuguesa a uma família cristã-nova que chega na Bahia na passagem do século XVII para o XVIII. Por meio dos processos dos Bernal Nunes de Miranda, o autor levanta questões relacionadas ao criptojudaísmo na Bahia, mesmo tendo passado mais de dois séculos desde a conversão forçada, bem como sobre o discurso da Inquisição contra as práticas judaizantes. A abordagem acerca do estatuto de pureza de sangue, que vigorou nas sociedades ibéricas como prérequisito para o acesso as instituições do Antigo Regime, também tem lugar de destaque no artigo, assim como os estudos do médico Francisco Bernal, em Salamanca, e a sua aproximação com Sebastião Monteiro da Vide, Arcebispo do Brasil de 1702 a 1722. Enfim, mediante o cotejamento de informações coletadas em fontes inquisitoriais, o autor demonstra como o ensinamento das cerimonias judaicas eram passadas, discute o papel da mulher na orientação religiosa e na organização cerimonial e ritualística, além de apresentar informações sobre as experiências dos acusados no interior do cárcere, onde eram submetidos a tormentos. O texto é rico em discussões e informações sobre relações familiares e fenômeno migratório, atividades econômicas, sociabilidade e poder na América portuguesa.

Voltada para o universo mineiro setecentista, por meio da documentação inquisitorial, a autora do artigo seguinte, Leticia Maia Dias, apresenta a história de um português que chegou ao Brasil em 1719 e, alguns anos depois, ocupou o cargo de escrivão da Casa de Moeda de Vila Rica. O texto, intitulado "Um bígamo nas Minas Gerais: a trajetória de Antônio José Cogominho", conta a trajetória desse reinol processado por crime de bigamia no final da primeira metade do século XVIII, uma vez que, já sendo casado no reino, casou-se novamente na capitania de Minas Gerais. Ao analisar o processo de Cogominho, a autora coloca em evidência características importantes da colônia e de sua relação com as instituições do Império Ultramarino. Além disso, a autora trabalha muito bem com a legislação referente ao crime de bigamia, transitando pelas Constituições Primeiras do Arcebispado da Bahia, pelas Ordenações do Reino e pelos Regimentos da Inquisição Portuguesa. A autora conclui que o delito de bigamia deve ser visto por dentro "da própria estrutura dos casamentos coloniais, uma vez que o ato de casar de novo evidenciava brechas inerentes aos processos matrimoniais que podem ter sido estrategicamente usadas pelos bígamos”.

O artigo intitulado "Contestação e memória do Tribunal do Santo Ofício: uma perspectiva protestante", escrito por Elizete da Silva, é muito oportuno para a conclusão da seção de artigos do dossiê. Ao analisar fontes escritas contra as práticas inquisitoriais do século XVIII, a autora traz à discussão, na perspectiva das ideias iluministas, a noção de liberdade de consciência e põe em evidência a trajetória do escritor Francisco Xavier de Oliveyra - de alcunha Cavaleiro de Oliveira -, feito réu e sentenciado em 1761 pelo Tribunal de Lisboa. Com esse estudo, a autora dá uma excelente contribuição para o estudo do protestantismo europeu, desde a sua origem, com o surgimento do luteranismo, perpassa a discussão sobre a extinção do Santo Ofício português e conclui com o nascimento de igrejas protestantes no Brasil, na segunda metade dos oitocentos. Para falar do protestantismo europeu e do discurso referente ao terror e à tirania da Inquisição, Elizete chama a atenção sobre a estratégia discursiva de disputa entre protestantismo e catolicismo, afirmando que a intolerância ocorreu dos dois lados. 
O dossiê se encerra com a entrevista, realizada pela equipe do Laboratório de Estudos, Documentação Inquisitorial e Sociedade de Antigo Regime (LEDISAR), com sede na Universidade Estadual do Sudoeste da Bahia, com a historiadora Patrícia Souza de Faria. Na entrevista, são abordados temas relativos às possiblidades e potencializados de desenvolvimento de pesquisas e projetos de ensino com base na documentação inquisitorial. Com ampla experiência na identificação e exploração de fontes relativas à presença da Inquisição no Oriente português, Patrícia Faria expõe sua trajetória acadêmica e fornece orientações para aqueles que queiram se aventurar nos estudos inquisitoriais.

A título de conclusão, submeto à reflexão dos leitores da Politeia dois documentos produzidos no apagar das luzes da Inquisição portuguesa, os quais são importantes para pensar a atuação desta instituição no mundo liberal. O primeiro é o processo de Hipólito José da Costa - redator do jornal Correio Braziliense, impresso entre 1808 e 1822 em Londres. O personagem foi preso nos cárceres da inquisição de Lisboa, em janeiro de 1803, por acusação de ser pedreiro-livre (maçom), mas fugiu em 1805. ${ }^{24}$ Conforme consta em seu processo, o crime tornou-se mais grave pelo fato de o indivíduo ter "graus superiores na Ordem Maçónica" e ter sido enviado como plenipotenciário pelo supremo Conselho Maçônico de Portugal ao Grande Oriente de Londres. Após a fuga dos Estaus, Hipólito foi para a Inglaterra, onde viveu até a sua morte, ocorrida em 1823. O segundo documento trata de uma anotação no último livro de Correspondências Expedida do tribunal de Lisboa. Os registros começaram a ser feitos em 7 de janeiro de 1802, enumerados e rubricados pelo inquisidor Manuel Estanislau Fragoso. A última anotação foi feita em 28 de fevereiro de 1821, portanto, a um mês da extinção do Santo Ofício Português. ${ }^{25} \mathrm{O}$ teor de uma carta enviada para Évora fornece informação sobre a soltura do réu Francisco de Almeida Nogueira, no dia 28 daquele mesmo mês. O primeiro individuo era o que se poderia chamar à época de "famoso"; o segundo nem tanto. Os processos aos quais eles foram submetidos revelam muito sobre os últimos lampejos do Santo Ofício.

\section{REFERÊNCIAS:}

ABREU, C. de (ed.). Primeira Visitação do Santo Oficio às partes do Brasil pelo licenciado Heitor Furtado de Mendonça. Confissões da Bahia, 1591-1592. São Paulo: Paulo Prado, 1922.

ASSIS, A. A. F. de. Macabéias da Colônia: Criptojudaismo Feminino na Bahia - séculos XVI e XVII. São Paulo: Alameda, 2012.

ASSIS, A. A. F. de. No interior do labirinto, o olho do vulcão: Revisitar os estudos inquisitoriais no Brasil e vislumbrar o futuro que tecemos. Ultramares, v. 1, p. 10-33, 2015.

BETHENCOURT, F. História das inquisições - Portugal, Espanha e Itália: séculos XV-XIX. São Paulo: Companhia das Letras, 2000.

24 ANTT, TSO, IL, Processo 17981.
25 IANTT, IL, Livro 69.

Pol. Hist. Soc., Vitória da Conquista, v. 20, n. 1, p. 8-22, jan.-jun. 2021. ISSN 2236-8094 
CALAINHO, D. B. O Arquivo Nacional da Torre do Tombo e a documentação da Inquisição Portuguesa na Época Moderna. Revista Electronica de Fuentes e Archivos, v. 10, p. 78-112, 2019.

CALAINHO, D. Agentes da Fé: familiares da Inquisição portuguesa no Brasil Colonial. Bauru: Edusc, 2006.

FALCON, F. Inquisição e poder: o regimento do Santo Ofício da Inquisição no contexto das reformas pombalinas (1774). In: NOVINSKY, A. e CARNEIRO, M. L. Tucci. (org.). Inquisição: ensaios sobre mentalidade, heresias e arte. São Paulo; Edusp; Rio de Janeiro: Expressão e Cultura, 1992, p. 116-139.

FEITLER, B. Nas malhas da consciência: Igreja e Inquisição no Brasil. São Paulo: Alamedas; Phoebus, 2007.

FRANÇA, Eduardo de Oliveira, SIQUEIRA, Sônia (org.). Segunda Visitação do Santo Ofício às partes do Brasil pelo Inquisidor e Visitador Marcos Teixeira. Livro das Confissões e Ratificações da Bahia, 1618-1620, Anais do Museu Paulista, XVII, 1963.

LAPA, J. R. do A. (org.). Livro da Visitação do Santo Ofício da Inquisição ao Estado do Grão-Pará: 1763-1769. Petrópolis: Vozes, 1978.

LIPINER, E. Santa Inquisição: terror e linguagem. Rio de Janeiro: Documentário, 1977.

MARCOCCI, G. A fundação da Inquisição em Portugal: um novo olhar. Lusitania Sacra, v. 23, p. 17-40, jan.-jun. 2011.

MARCOCCI, G.; PAIVA, J. P. História da Inquisição Portuguesa: 1536-1821. Lisboa: A Esfera dos Livros, 2013.

MOTT, L. Babia: Inquisição e Sociedade. Salvador: Edufba, 2010.

MOTT, L.: Regimentos dos Comissários e escrivães do seu cargo, dos qualiflcadores e dos familiares do Santo Ofício. Salvador: Centro de Estudos Baianos, 1990.

NOVINSKY, A. Inquisição: inventários de bens confiscados a cristãos novos. Fontes para a história de Portugal e do Brasil (Brasil - Século XVIII). Lisboa: Imprensa Nacional/Casa da Moeda, 1978.

PEREIRA, A. M. S. Terceira Visitação do Santo Ofício às partes do Brasil. Capitanias do sul, 1627-1628. Politeia:, Vitória da Conquista, v. 11, n. 1, p. 35-60, 2011. Disponível em: http://periodicos.uesb.br/index.php/politeia/article/viewFile/1099/1471

RODRIGUES, A. C. Limpos de Sangue: Familiares do Santo Ofício, Inquisição e Sociedade em Minas Colonial. São Paulo: Alameda, 2011.

SARAIVA, A. J. Inquisição e cristãos-novos. Lisboa: Estampa, 1994. (Col. Histórias de Portugal).

SILVA, E. da. Combates pela fé nos domínios ibéricos: confitentes arrependidos na Bahia Colonial. In: SOUZA, G. M. B.; MANSO, M. de D. (org.). Difusão da fé por entre povos e lugares: instituições, religião e religiosidades no império português (Séculos XVI-XIX). Vitória da Conquista: Edições Uesb, 2020. p. 38-73. E-book disponível em: http://www2.uesb.br/editora/wp-content/uploads/Difus\%C3\%A3oda-f\%C3\%A9_miolo.pdf

SIQUEIRA, S. A Inquisição Portuguesa e a Sociedade Colonial. São Paulo: Ática, 1978.

SIQUEIRA, S. Os Regimentos da Inquisição. Revista do Instituto Histórico e Geográfico Brasileiro, ano 157, n. 392, p. 495-1020, jul-set. 1996. 
SOUZA, G. M. B. Uma trajetória racista: o ideal de pureza de sangue na sociedade ibérica e América portuguesa. Politeia, Vitória da Conquista, v. 8, n. 1, p. 83-103, 2008.

SOUZA, G. M. B. Para remédio das almas: Comissários, Qualificadores e Notários na Bahia Colonial. Vitória da Conquista: Edições Uesb, 2014.

VAINFAS, R. (org.). Confissões da Babia: Santo Ofício da Inquisição de Lisboa. São Paulo: Companhia das Letras, 1997.

VAQUINHAS, N. M. C. Da comunicação ao sistema de informação: o Santo Ofício e o Algarve (1700-t1750). Lisboa: Edições colibri/CIDEHUS/UE, 2010.

WADSWORTH, J. E. Agents of Orthodoxy: Honor, Status, and the Inquisition in Colonial Pernambuco, Brazil. Lanham, MD: Rowman \& Littlefield. 2007. 